Association for Information Systems

AIS Electronic Library (AISeL)

\title{
Developing Digitalization Mindset and Capabilities: Preliminary Results of an Action Research Study
}

Ralf Plattfaut

South Westphalia University of Applied Sciences, Process Innovation \& Automation Lab,Soest, Germany

Vincent Borghoff

South Westphalia University of Applied Sciences, Process Innovation \& Automation Lab,Soest, Germany

Follow this and additional works at: https://aisel.aisnet.org/wi2021

Plattfaut, Ralf and Borghoff, Vincent, "Developing Digitalization Mindset and Capabilities: Preliminary Results of an Action Research Study" (2021). Wirtschaftsinformatik 2021 Proceedings. 1.

https://aisel.aisnet.org/wi2021/KDigitalEducation15/Track15/1

This material is brought to you by the Wirtschaftsinformatik at AIS Electronic Library (AISeL). It has been accepted for inclusion in Wirtschaftsinformatik 2021 Proceedings by an authorized administrator of AIS Electronic Library (AISeL). For more information, please contact elibrary@aisnet.org. 


\title{
Developing Digitalization Mindset and Capabilities: Preliminary Results of an Action Research Study
}

\author{
Ralf Plattfaut ${ }^{1}$, Vincent Borghoff ${ }^{1}$ \\ ${ }^{1}$ Fachhochschule Südwestfalen, Process Innovation \& Automation Lab, Soest, Germany \\ \{plattfaut.ralf,borghoff.vincent\}@ fh-swf.de
}

\begin{abstract}
Organizations around the globe are faced with the digital transformation. However, many of these organizations, lack the corresponding individual skills and mindsets as well as the organizational capabilities to drive digital transformation. This short paper reports on preliminary results of an action research study. We conceptualize organizational digitalization capabilities as dynamic capabilities and create a theoretical understanding of these capabilities with their corresponding microfoundations, i.e., the individual employee's skills and mindset. Based on an in-depth nine months' action research study we aim to show in how far outside consulting support will change individuals' mindsets and skills as well as organizational capabilities. We thus contribute to both theory on organizational capability-building as well as dynamic capability theory.
\end{abstract}

Keywords: Digitalization, Skills, Mindset, Dynamic Capabilities.

\section{Introduction}

Virtually all organizations around the world are currently dealing with the digital transformation. However, organizations often lack capabilities to drive this digitalization on their own. Academic literature as well as general media has reported on many cases where companies and organizations seek outside help to transform themselves $[1,2]$, especially as individual skills and mindsets of employees with regards to digitalization are missing, too. Exemplarily, current employees "may have a [...] less tech-savvy mindset and may lack the required technological capabilities to cope with the upcoming changes" [3]. Other authors agree that the digital transformation requires different skillsets: Domain experts need to be able to navigate the digitalized world and technical specialists need to have a digital mindset [4].

This is especially true for Small to Medium-Sized Enterprises (SME). They also face an increasing importance of digitalization, a lack of corresponding capabilities, and a need for improvement in employees' skills and mindsets and rely on external support from consultants or software vendors. In this study, we aim at deepening our understanding of the impact of external digitalization consulting on individual skills, individual mindset, and organizational capabilities. We employ the dynamic capability theory as a theoretical frame and aim at contributing a deeper understanding of microfoundations of dynamic capabilities. To achieve this research objective, we

16th International Conference on Wirtschaftsinformatik,

March 2021, Essen, Germany 
conduct a nine month qualitative action research (AR) study [5]. In this short paper we describe the results of the first phase (diagnoses and action planning) and give an outlook on the later phases of our research.

\section{Theoretical Background: Organizational Digitalization Capabilities and Individual Mindset and Skills}

Like individual members, organizations also have specific capabilities to achieve an intended outcome. Especially in fast changing environments, the necessity of adaptation and innovation is urgent. Organizational capabilities are the ability to address these necessities and to achieve competitive advantages [6]. They can be understood as dynamic capabilities [7, 8], which are defined as 'the firm's ability to integrate, build, and reconfigure internal and external competences to address rapidly changing environments" [9]. These organizational dynamic capabilities can be disaggregated into sensing, seizing and transforming [10-12]. Sensing represents the ability to recognize opportunities and threats, seizing the ability to address sensed opportunities, and transforming the process of modifying the resource base accordingly.

Sensing, seizing, and transforming require in turn abilities on an individual level [13-16], e.g., executives' cognitive capabilities.

Prior research showed that the motivation, skills, and expertise of managers are crucial for sensing and seizing in volatile environments [13]. Blyler and Coff [17] argued that social capital is a necessary (though not sufficient) condition for the existence of a dynamic capability, as only through social interaction resources are connected and recombined. The importance of this social factor becomes more apparent when considering heterogeneous individual knowledge, mindsets and skills between individuals and organizational positions [18]. This emphasizes a more individual view on the foundations of dynamic capabilities, as routines and organizational attitudes arise out of mindset and skill of individuals [14].

The concept of mindset bases in the field of cognitive psychology [19]. We define the mindset of an individual as their set of beliefs, norms, rules, values [20, 21]. Mindsets act as filters for external influences. Their foundations lie in past experiences. When facing new impressions or actions, those may be rejected or lead to an adaption in mindset $[19,22]$. The individual and organizational mindset plays a big role in achieving successful digital transformation [3, 20]. Especially flexibility and changeorientation in mindset is seen as a key factor for success [4, 23]. Solberg et al. distinguish four different types of digital mindsets of individual employees and argue that more digital-positive mindsets need to flourish [20]. We see the individual mindset as one important microfoundation of organizational digitalization capabilities.

The second microfoundation of organizational digitalization capability is formed through the individual digitalization skill of employees and management [24]. On individual level, where the capabilities are grounded, one can distinguish between expertise and managerial skills [24]. With regards to IT and digitalization, expertise includes technical skills, like knowledge of programming languages, operational systems or databases. In addition knowledge in technology management, as well as 
interpersonal skills and business functional knowledge is also shown to be important [25].

\section{Research Approach}

Action research (AR) first appeared in the 1940s. The concept was coined by the social psychologist Kurt Lewin [26], who was studying how social change can be facilitated [5]. The method itself spread broadly into other research fields and became popular in Information Systems research in the beginning 1980s. It follows an interventionist approach on gathering knowledge. AR as a method is also ideal for creating and analyzing change in organizations, which is a main focus of this study [27].

The study follows a linear, one-cyclic, AR approach $[5,28]$ with three phases of data collection [28], encapsulating the five steps of diagnosing, action planning, action taking, evaluation, and specifying learning [29] (Figure 1). In this study we focus on SMEs as these allow studying both individual skills and mindset of a larger proportion of the workforce and organizational capabilities in detail. In such setting, the planned intervention will be more visible and thus the results appear to be magnified. Moreover, the organization needed to be in close proximity to the main researchers to ensure good availability of data. For these reasons, we selected GROW as our case study organization. GROW is a regional business development agency. Although GROW is organized as a private company, it is owned by the local and regional administrations from the corresponding region. The main goals for GROW are to attract new firms to the region and help the existing firms to prosper. GROW has 15 employees who work in the corresponding knowledge-intensive processes.

The first of the three phases covers the diagnosing and action planning phases. Here, we are able to observe employees, gather information from informal CEO discussions, and conduct four semi-structured interviews with employees (referenced as [I1] to [I4] below). The interviewees were one internal project manager and three employees who work with existing firms to enable their growth (two focused on production companies, one on healthcare). Each interview lasted between 38 and 56 minutes. The interviews were transcribed (between 10 to 13 pages of transcript) and carefully read by both authors and the interviewee.

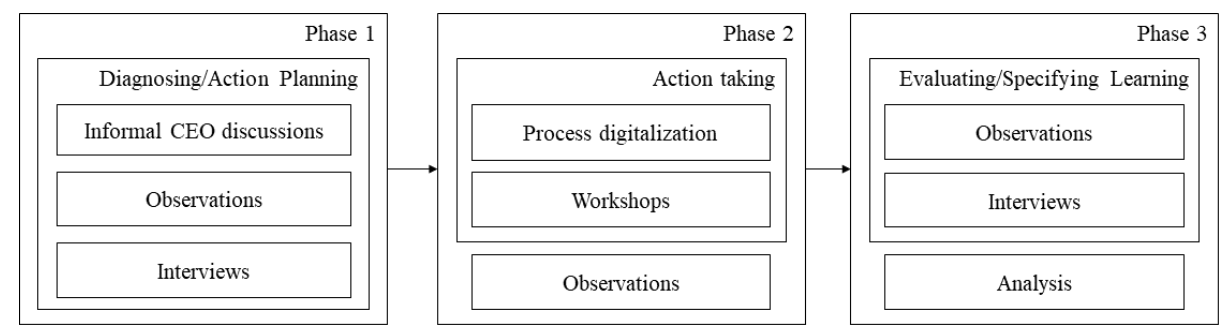

Figure 1. Research and data collection approach 
The second phase (action taking) includes the digitalization of three business processes as well as the conduction of topic specific workshops. We use light-weight IT, e.g., Robotic Process Automation, to redesign and automate administrative tasks identified in coordination with the management. Additionally, we will create meeting notes from every interaction with employees. These notes will concentrate on the content of the interaction and on potential observations regarding skills and mindset. During the third phase we collect further data through interviews. All qualitative date will be analyzed by a team of (then) four researchers. Two of these researchers will not be involved in data collection and the intervention to prevent researcher's bias and ensure fresh perspectives on the data at hand as well as potential alternative explanations [30].

\section{$4 \quad$ Preliminary Results and Concluding Discussion}

In the following we present our preliminary results from the first phase of our research. We have identified seven themes concerning the current state of the organization with regards to digitalization (Themes 1 and 2), organizational capabilities (Themes 3 and 4) and employees' individual mindset and skills Themes 5-7).

Theme 1: Share of administrative routines. All interviewed employees describe a relatively big amount of administrative work. These activities are considered to be nonvalue adding and take time and focus away from the original task, i.e., to attract new firms to the region and help existing firms develop. As one employee put it: "In the area of administrative tasks, I would say, they have a share of 40 to $50 \%$ of total" [I3]. These administrative activities originate either from internal inefficiencies due to a lack of process digitalization or from complex interactions with external parties such as the shareholders (local district authority) or funding organizations on state or federal level.

Theme 2: Front runner among the public organizations in the region. Although the high share of administrative routines could be reduced through additional internal digitalization, GROW can be seen as a frontrunner in digitalization when compared to the main shareholder, i.e., the district authority. This becomes especially visible as for some processes the district authority acts as a service provider. "Everything that has to do with the district authority is, in fact, more likely to have paper-based interface." [I1] In contrast to this, GROW has started to digitalize their internal processes to a greater extent. Exemplarily, the organization switched to a modern full-fledged Office 365 environment and is currently migrating to a cloud-based CRM solution.

Theme 3: Low internal technical digitalization capabilities. Two observations highlight that GROW has very limited internal digitalization capabilities. Firstly, GROW has no internal IT department but depends on external providers. These IT providers are either part of the district authority, e.g., for telephone services, or are sourced on the external market, e.g., for the CRM system. This reliance on different external providers hinders further digitalization. Exemplarily, "because the [telephone] switchboard is currently still in the district authority, there is no call register in our CRM system" [I3].

Theme 4: Digitalization skills or capabilities are no recruiting criteria. In addition, GROW does not include digitalization skills in their recruitment criteria. Both 
interviews and analyzed job advertisements show that specific IT or digitalization knowledge is not required from potential applicants.

Theme 5: Mindset of Passenger and not of Driver. Employees see themselves as pure users of digital technologies. There is no impetus for self-driven digitalization. Exemplarily, one employee sees himself as "one of those who use digital solutions with pleasure, when they are offered. But I do not start, conceptualize or develop something myself or make any innovations in that field" [I2]. There is a strong understanding that someone should digitalize GROW, as long as these digital solutions are easy to use.

Theme 6: Innovation is driven bottom-up as well as top-down. Building on the fifth theme, we could also observe that innovation is mainly driven by the top management. There are rare instances when ideas also are generated by employees, but only in specific domains. Digital innovations "which affect the entire GROW workforce are ultimately initiated by the management. So the individual ideas may come from different people, but the actual impulse comes from the management" [I4].

Theme 7: Low individual IT development skills. As already mentioned, the individual IT development skills are fairly low. Most interviewees see themselves as interested users, but have no, or nearly no capability in terms of development (I1, I2 and I4). I3 has some basic IT background, but is no real programmer. Guided, less code-heavy development is possible for him, "but in general, when it comes to programming skills, I would say that I am still scratching the surface" [I4].

Our preliminary results indicate that the dynamic digitalization capabilities of GROW are on intermediate levels. While with regards to sensing of new opportunities, some abilities exist, the contrary is true for the seizing and transforming abilities. Here, GROW heavily relies on external parties. In line with our conceptualization, the preliminary results also suggest that the individual mindset and capabilities of the employees with regards to digitalization is, at least in parts, on a level that can be improved. The mindset of employees regarding digital change at GROW is not active.

Based on these findings we aspire to reach a deeper understanding of the development of organizational capabilities through the underlying microfoundations of individual skills and mindsets. The next step in our research process is the intervention phase. This includes the active analysis of selected processes and the corresponding development of digital automation solution. During the intervention, qualitative data on the development of mindsets and skills will be collected continuously. The third data collection phase is scheduled after the implementation of the solutions. The used interview guideline will be adapted to cover planned future developments within the organizations IT and process landscape. The collected data will be aggregated and analyzed regarding changes in mindset and capabilities on both the individual and the organizational level. Moreover, we will regularly revisit GROW to understand the development of organizational capabilities.

Both intermediate and final results will be limited to a certain extent. Firstly, there is the risk of residual researcher's bias. We hope to overcome this bias to a large extent through a delineation between researchers actively involved in the intervention phase and researchers focusing on data analysis. Secondly, as the results are and will be generated from a single organization, generalizability needs to be further discussed. 


\section{References}

1. Plattfaut, R.: Robotic Process Automation - Process Optimization on Steroids? In: Krcmar, H., Fedorowicz, J., Boh, W.F., Leimeister, J.M., Wattal, S. (eds.) Proceedings of the 40th International Conference on Information Systems, ICIS 2019, . Association for Information Systems (2019)

2. Smith, H.A., Watson, R.T.: Digital Transformation at Carestream Health. MIS Quarterly Executive 18 (2019)

3. Matt, C., Hess, T., Benlian, A.: Digital Transformation Strategies. Bus Inf Syst Eng 57, 339-343 (2015)

4. Kane, G.C., Palmer, D., Nguyen Phillips, A., Kiron, D., Buckley, N.: Achieving digital maturity: Adapting Your Company to a Changing World. MIT Sloan Management Review 2017 (2017)

5. Baskerville, R.L., Wood-Harper, A.T.: A critical perspective on action research as a method for information systems research. Journal of Information Technology 11, 235-246 (1996)

6. Dosi, G., Nelson, R.R., Winter, S.G.: Introduction: The nature and dynamics of organizational capabilities. In: Dosi, G., Nelson, R.R., Winter, S.G. (eds.) The nature and dynamics of organizational capabilities. Oxford Univ. Press, Oxford (2009)

7. Priem, R.L., Butler, J.E.: Is the Resource-Based "View" a Useful Perspective for Strategic Management Research? AMR 26, 22-40 (2001)

8. Helfat, C.E., Peteraf, M.A.: The dynamic resource-based view: capability lifecycles. Strat. Mgmt. J. 24, 997-1010 (2003)

9. Teece, D.J., Pisano, G., Shuen, A.: Dynamic capabilities and strategic management. Strat. Mgmt. J. 18, 509-533 (1997)

10. Teece, D.J.: Explicating dynamic capabilities: the nature and microfoundations of (sustainable) enterprise performance. Strat. Mgmt. J. 28, 1319-1350 (2007)

11. Plattfaut, R., Niehaves, B., Voigt, M., Malsbender, A., Ortbach, K., Poeppelbuss, J.: Service Innovation Performance and Information Technology: An Empirical Analysis From the Dynamic Capability Perspective. Int. J. Innov. Mgt. 19, 1550038 (2015)

12. Barreto, I.: Dynamic Capabilities: A Review of Past Research and an Agenda for the Future. Journal of Management 36, 256-280 (2010)

13. Zahra, S.A., Sapienza, H.J., Davidsson, P.: Entrepreneurship and Dynamic Capabilities: A Review, Model and Research Agenda*. J Management Studies 43, 917-955 (2006)

14. Felin, T., Foss, N.J.: Strategic organization: a field in search of microfoundations. Strategic Organization 3, 441-455 (2005)

15. Eisenhardt, K.M., Furr, N.R., Bingham, C.B.: CROSSROADSMicrofoundations of Performance: Balancing Efficiency and Flexibility in Dynamic Environments. Organization Science 21, 1263-1273 (2010)

16. Helfat, C.E., Peteraf, M.A.: Managerial cognitive capabilities and the microfoundations of dynamic capabilities. Strat. Mgmt. J. 36, 831-850 (2015) 
17. Blyler, M., Coff, R.W.: Dynamic capabilities, social capital, and rent appropriation: ties that split pies. Strat. Mgmt. J. 24, 677-686 (2003)

18. Felin, T., Powell, T.C.: Designing Organizations for Dynamic Capabilities. California Management Review 58, 78-96 (2016)

19. Gupta, A.K., Govindarajan, V.: Cultivating a global mindset. AMP 16, 116-126 (2002)

20. Solberg, E., Traavik, L.E.M., Wong, S.I.: Digital Mindsets: Recognizing and Leveraging Individual Beliefs for Digital Transformation. California Management Review 62, 105-124 (2020)

21. Töytäri, P., Turunen, T., Klein, M., Eloranta, V., Biehl, S., Rajala, R.: Aligning the Mindset and Capabilities within a Business Network for Successful Adoption of Smart Services. J PROD INNOV MANAG 35, 763-779 (2018)

22. Walsh, J.P., Charalambides, L.C.: Individual and Social Origins of Belief Structure Change. The Journal of social psychology 130, 517-532 (1990)

23. Hartl, E., Hess, T.: The Role of Cultural Values for Digital Transformation: Insights from a Delphi Study. In: Twenty-third Americas Conference on Information Systems, AMCIS 2017, pp. 1-10. Boston, USA (2017)

24. Aral, S., Weill, P.: IT Assets, Organizational Capabilities, and Firm Performance: How Resource Allocations and Organizational Differences Explain Performance Variation. Organization Science 18, 763-780 (2007)

25. Kim, G., Shin, B., Kim, K., Lee, H.: IT Capabilities, Process-Oriented Dynamic Capabilities, and Firm Financial Performance. JAIS 12, 487-517 (2011)

26. Lewin, K.: Action Research and Minority Problems. Journal of Social Issues 2, 34-46 (1946)

27. Baskerville, Myers: Special Issue on Action Research in Information Systems: Making IS Research Relevant to Practice: Foreword. MIS Quarterly 28, 329 (2004)

28. Baskerville, R., Wood-Harper, A.T.: Diversity in information systems action research methods. Eur J Inf Syst 7, 90-107 (1998)

29. Susman, G.I.: Action research: a sociotechnical systems perspective. In: Morgan, G. (ed.) Beyond method. Strategies for social research. Sage, Beverly Hills, Calif. (1985)

30. Levin, M.: Academic integrity in action research. Action Research 10, 133-149 (2012) 